\title{
Technical Note: Performance of Chemical Ionization Reaction Time-of-Flight Mass Spectrometry (CIR-TOF-MS) for the measurement of atmospherically significant oxygenated volatile organic compounds
}

\author{
K. P. Wyche ${ }^{1}$, R. S. Blake ${ }^{1}$, A. M. Ellis ${ }^{1}$, P. S. Monks ${ }^{1}$, T. Brauers ${ }^{2}$, R. Koppmann ${ }^{2, *}$, and E. C. Apel ${ }^{3}$ \\ ${ }^{1}$ Department of Chemistry, University of Leicester, Leicester, UK \\ ${ }^{2}$ Institut für Chemie und Dynamik der Geosphäre II, Forschungszentrum Jülich, Jülich, Germany \\ ${ }^{3}$ National Centre for Atmospheric Research, Boulder, Colorado, USA \\ *now at: Bergische Universität Wuppertal, Fachbereich C, Atmosphärenphysik, Wuppertal, Germany
}

Received: 25 September 2006 - Published in Atmos. Chem. Phys. Discuss.: 12 October 2006

Revised: 21 December 2006 - Accepted: 1 February 2007 - Published: 8 February 2007

\begin{abstract}
The performance of a new chemical ionization reaction time-of-flight mass spectrometer (CIR-TOF-MS) utilising the environment chamber SAPHIR (Simulation of Atmospheric Photochemistry In a large Reaction ChamberForschungzentrum Jülich, Germany) is described. The work took place as part of the ACCENT (Atmospheric Composition and Change the European NeTwork for excellence) supported oxygenated volatile organic compound (OVOC) measurement intercomparison during January 2005. The experiment entailed the measurement of 14 different atmospherically significant OVOCs at various mixing ratios in the approximate range $10.0-0.6 \mathrm{ppbV}$. The CIR-TOF-MS operated throughout the exercise with the hydronium ion $\left(\mathrm{H}_{3} \mathrm{O}^{+}\right)$as the primary chemical ionization $(\mathrm{CI})$ reagent in order to facilitate proton transfer to the analyte OVOCs. The results presented show that the CIR time-of-flight mass spectrometer is capable of detecting a wide range of atmospheric OVOCs at mixing ratios of around $10 \mathrm{ppbV}$ in "real-time" (i.e. detection on the one-minute time scale), with sub-ppbV measurement also achieved following an increase in averaging time to tens of minutes. It is shown that in general OVOC measurement is made with high accuracy and precision, with integration time, mixing ratio and compound dependent values as good as $4-13 \%$ and $3-15 \%$ respectively. It is demonstrated that CIR-TOF-MS has rapid multi-channel response at the required sensitivity, accuracy and precision for atmospheric OVOC measurement.
\end{abstract}

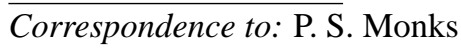

(p.s.monks@le.ac.uk)

\section{Introduction}

Oxygenated volatile organic compounds (OVOCs) are ubiquitous in the troposphere (Singh et al., 1995). They have both primary and secondary sources, being emitted by anthropogenic and biogenic processes, as well as being formed from the gas-phase oxidation of parent hydrocarbons. OVOCs exist in the atmosphere at trace levels in the parts per trillion to parts per billion (by volume) range and are key players in many atmospheric processes from the production of tropospheric ozone (Monks, 2005) to secondary organic aerosol formation (Kalberer et al., 2004).

Current methods for measuring OVOCs and VOCs (volatile organic compounds) include gas chromatography techniques (e.g. Lewis et al., 2005), differential optical absorption spectroscopy (DOAS) (e.g. Sinreich et al., 2005) and more recently proton transfer reaction mass spectrometry (PTR-MS) (e.g. Lindinger et al., 1993; Warneke et al., 2001). The modus operandi of PTR-MS is the chemical ionization, by proton transfer, of a gas sample inside a drift tube. The fixed length of the drift tube provides a fixed reaction time for the ions as they pass along the tube: the reaction time can be measured or it can be calculated from ion transport properties. If the proton donor is present in large excess over the acceptor molecules, then a measurement of the ratio of donor/protonated acceptor ion signals allows the concentration of the acceptor molecules to be calculated. The PTRMS method allows fast real-time measurements of a range of VOCs in air including OVOCs. On-line methods offer a new dimension to VOC analysis as they can begin to assess the rapid fluctuations in concentration with time.

Published by Copernicus GmbH on behalf of the European Geosciences Union. 
In conventional PTR-MS, the mass spectrometer has been a quadrupole (e.g. Hansel et al., 1995) or more recently an ion-trap (Warneke et al., 2005). Our group demonstrated the first PTR-MS system using TOF-MS (Blake et al., 2004). More recently Ennis et al. (2005) and Inomota et al. (2006) have developed similar systems. TOF-MS comes into its own when dealing with complex mixtures since an entire spectrum is, in effect, captured in an instant. Furthermore, there is no upper mass limit and the standard resolution in TOF-MS is usually far higher than in quadrupole mass spectrometers. These characteristics confer a number of potentially important advantages for the analysis of complex mixtures. More recently, PTR-TOF-MS has been generalised to include other chemical ionization reagents, such as $\mathrm{NO}^{+}$and $\mathrm{O}_{2}^{+}$(Wyche et al., 2005 and Blake et al., 2006). Consequently, this more general technique has been referred to as chemical ionization reaction mass spectrometry, or CIR-MS for short.

A number of extensive intercomparison exercises have been carried out for the measurement of non-methane hydrocarbons (NMHCs) (e.g. Apel et al., 2003 and Plass-Dülmer et al., 2006 and references therein). The aim of these intercomparison campaigns has been to assess the accuracy and comparability of NMHC measurements from groups around the globe. Many of these exercises have concentrated on the measurement of NMHCs from various multi-component mixtures and canisters of ambient air. These comparisons have been useful in highlighting a wide range of sampling and analytical problems. However, to date there have been no similar exercises for OVOCs, which present a particular analytical challenge owing to their polar nature and the potential for interference from various sampling artefacts (e.g. Northway et al., 2004)).

As part of the ACCENT QA/QC project (see www. accent-network.org), an OVOC comparison exercise was organised in January 2005 (Apel et al., 2007¹ ). Fourteen atmospherically significant OVOC species were selected for intercomparison including aldehydes, ketones and alcohols, of both biogenic and anthropogenic origin (see Table 1). Two NMHC compounds (n-butane and toluene) were also included in the study to act as tracers in order to monitor the dilution of the chamber air, with toluene specifically chosen for the benefit of PTR-MS instruments, which are unable to detect short chain alkanes. The experiment used a large atmospheric simulation chamber as the sample reservoir, which provided the ability to alter sample matrix, humidity and ambient ozone levels.

This paper details the results, performance and validation of a real-time sampling chemical ionization reaction timeof-flight mass spectrometry system, operating in the proton transfer mode for the determination of OVOC concentrations. As will be described, this study demonstrates that CIR-

\footnotetext{
${ }^{1}$ Apel, E. C., et al.:Intercomparisons of oxygenated volatile organic (OVOC) measurements at the SAPHIR atmosphere simulation chamber, paper in preparation, 2007.
}

TOF-MS is a highly effective tool for quantifying a multitude of OVOCs with good time resolution (ca. 1-10 min depending on sensitivity and concentration of the compound under inspection). This is an important finding which provides a firm foundation for the real-time analysis of OVOCs in complex trace gas mixtures such as atmospheric air. The multiinstitution comparison is the subject of another paper (Apel et al., $2007^{1}$ ).

\section{Experimental}

\subsection{The CIR-TOF-MS instrument}

The chemical ionization reaction mass spectrometer used in this work is shown in outline in Fig. 1. It comprises a radioactive ion source, an analyte gas inlet and a drift cell region coupled to an orthogonal time-of-flight mass spectrometer (Blake et al., 2004).

The ion source/drift cell assembly, constructed in-house and based on the design of Hanson and co-workers (Hanson et al., 2003), employs a radioactive strip of ${ }^{241} \mathrm{Am}$ in order to produce the CI reagent. In the case of hydronium generation, the $\alpha$ particles emitted (with energies of the order $5 \mathrm{MeV}$ ) facilitate ionization of water vapour, which is supplied to the source region at a rate of $52 \mathrm{sccm}$ by bubbling a high purity nitrogen carrier gas through a vessel of deionized water $(15 \mathrm{M} \Omega)$. With water molecules present in excess in the ion source region, hydronium ions are subsequently produced

The entire ion source region is directly coupled to a reaction drift cell, which is approximately $10 \mathrm{~cm}$ in length and consists of a series of seven stainless steel electrodes separated by five static dissipative Teflon spacers. A positive potential difference of the order $2700 \mathrm{~V}$ is distributed across the entire electrode array in order to generate a potential gradient along the longitudinal axis of the assembly. The resultant electric field acts to guide the ions through the drift cell and into the transfer optics of the mass spectrometer (via a $200 \mu \mathrm{m}$ aperture), as well as helping to inhibit hydroniumwater cluster ion $\left(\mathrm{H}_{3} \mathrm{O}^{+} .\left(\mathrm{H}_{2} \mathrm{O}\right)_{n}\right)$ formation.

After leaving the drift cell, the continuous ion beam passes through a differentially pumped chamber (path length approximately $2 \mathrm{~cm}$ ) before undergoing collimation during transit through a three-element Einzel lens. The extraction of ions for analysis is facilitated by the application of a rapidly pulsed electric field whose vector is perpendicular to the direction of the continuous ion beam. Following extraction an ion packet undergoes further acceleration and then $x y$ steering before entering a large-bore reflectron time-offlight mass spectrometer (Model: P-4500-A, Kore Technology; Ely, UK). A microchannel plate detector is employed for ion detection. For the OVOC intercomparison exercise all mass spectra were recorded for an averaging period of $60 \mathrm{~s}$ and over the mass range $0-143 \mathrm{Da}$. Over this specific mass 


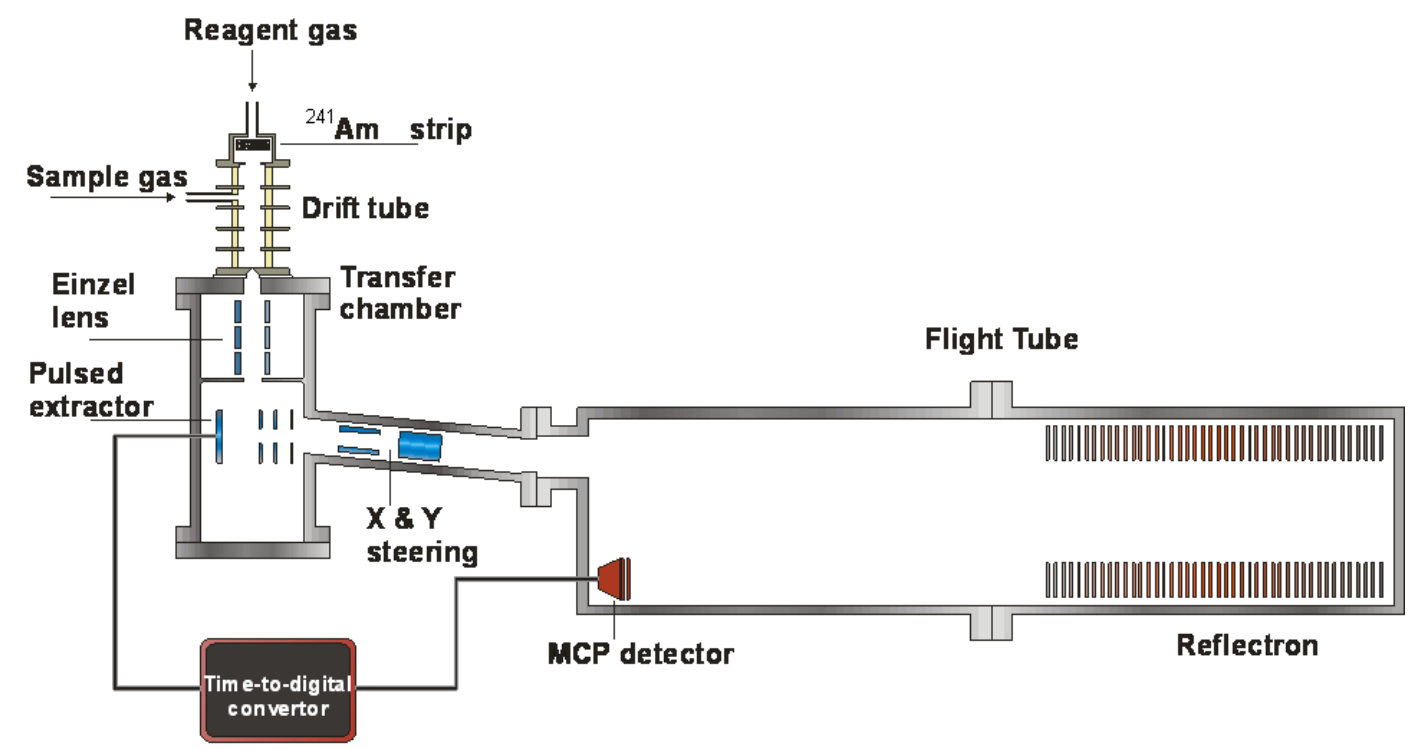

Fig. 1. Schematic representation of the CIR-TOF-MS system.

interval the instrument operates at a frequency of approximately $10^{4}$ scans s $^{-1}$, with a duty cycle of approximately $2 \%$.

The sample gas containing the OVOCs was delivered to the drift cell at a flow rate of $275 \mathrm{sccm}$ via a common insulated glass manifold and a $2 \mathrm{~m}$ long Teflon tube, which was heated to $40^{\circ} \mathrm{C}$. The combined reagent and sample gas flows provided a drift cell operating pressure between 7 and 8 mbar and hence an average drift cell $E / N$ ratio (where $E$ is the electric field and $N$ is the gas number density) of $\sim 147 \mathrm{Td}$, where $1 \mathrm{Td}=10^{-17} \mathrm{~V} \mathrm{~cm}^{2}$. Under such conditions the residence time of ions in the drift cell is of the order $0.05 \mathrm{~ms}$.

The CIR-TOF-MS weighs approximately $250 \mathrm{~kg}$ and has dimensions $1.9 \times 0.8 \times 1.8 \mathrm{~m}$. The instrument power consumption is $3.7 \mathrm{~kW}$.

2.2 The OVOC intercomparison experimental design and procedure

The SAPHIR smog chamber in which the intercomparison experiments were conducted is an outdoor facility consisting of a double-lined cylindrical bag constructed from FEP Teflon, with a wall thickness of $150 \mu \mathrm{m}$ and a volume of $270 \mathrm{~m}^{3}$ (20 $\mathrm{m}$ in length with a diameter of $5 \mathrm{~m}$ ) (Karl et al., 2004). The surface area to volume ratio in SAPHIR $\left(0.88 \mathrm{~m}^{-1}\right)$ is relatively small when compared to other environment chambers, allowing wall effects to be minimized. The chamber bag is held by a large metal frame incorporating a staged series of louvers that shield the sample gas matrix from solar radiation when required. SAPHIR experiments are conducted at ambient atmospheric pressure and temperature; the facility employs no internal heating system.
For the intercomparison experiments, trace gas delivery to the chamber took place via syringe injection of the liquid $\mathrm{OVOCs}^{2}$ into a heated injector port, which facilitated their volatilisation before entry into the bag. Total time for OVOC injection was of the order of 1 hour. Once inside the chamber, all gases were mixed by a series of mechanical fans, with chamber characterisation suggesting that a minimum mixing time of $30 \mathrm{~min}$ is required in order for the sample matrix to become homogeneous. The precision of OVOC addition via this method is at most 20\% (Wegener and Holzke, personal communication, 2004).

Ozone used in chamber experiments was supplied from a silent discharge ozonator, held under pure $\mathrm{O}_{2}$ in order to reduce possible impurities and contamination. Chamber humidification was facilitated by vaporising (Dampf-OMat) ultra pure deionised water (Milli-Q, Millipore), through which a continuous stream of high purity nitrogen (purity grade 7.0) was passed to remove dissolved trace impurities.

The OVOC measurement intercomparison exercise was designed such that four main experiments would be conducted, each approximately a single day in duration. The conditions of the synthetic air sample matrix were varied between experiments in order to explore the effects of humidity and ozone on the ability of the instruments to reliably monitor the target compounds. The details of conditions employed during each experiment were as follows:

- Experiment 1 (Chamber blank): Dry synthetic air $\left(\mathrm{N}_{2}: \mathrm{O}_{2}\right.$ ratio of $80: 20$, purity grade 7.0$)$ followed by hu-

\footnotetext{
${ }^{2}$ Excluding formaldehyde, which was generated via the pyrolysis of solid paraformaldehyde.
} 


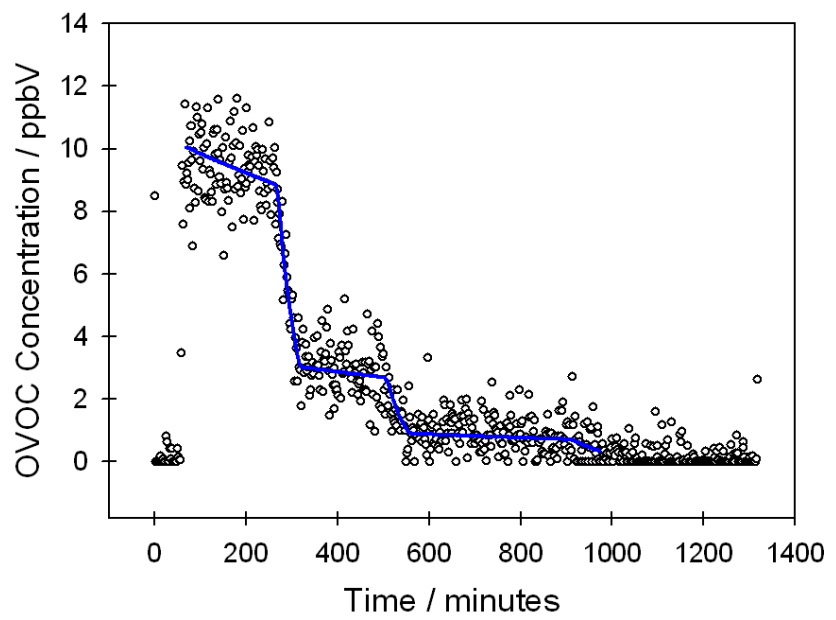

Fig. 2. Comparison of the CIR-TOF-MS measured concentration of acetaldehyde (circle points) versus time with the estimated chamber concentrations (blue line) during experiment 2.

midification (approximately 80-90\%) and ozone addition (approximately $50 \mathrm{ppbV}$ ). No OVOC injection.

- Experiment 2: Target OVOCs sampled from a dry synthetic air matrix. No humidification or ozone addition.

- Experiment 3: Target OVOCs sampled from a moist synthetic air matrix (relative humidity $60-100 \%$ ). No ozone addition.

- Experiment 4: Target OVOCs sampled from a moist synthetic air matrix (relative humidity 50-80\%) containing approximately $40-50 \mathrm{ppbV}$ ozone.

All experiments were conducted under dark conditions with the louvre closed.

In order to provide an instrument and chamber background and hence to facilitate removal of any possible contaminants or artefacts from the final data, the chamber air was measured for 3-4 h at the start of each experiment and before the injection of all test OVOCs. This information was subsequently employed to subtract away any unwanted background from the final OVOC measurement. A typical background mass spectrum is given in Fig. 4b. When conducting observations of ambient air, an instrument baseline is typically obtained at regular intervals during measurement by passing the sample gas first through a hydrocarbon trap to filter out the trace species of interest. Again subtraction of the background will aid the removal of contamination or artefacts from the final data.

The combined CIR-TOF-MS and chamber baseline was stable for the majority of mass channels throughout the intercomparison campaign. When background mass scans were integrated over successive one minute periods the standard deviation of the total ion count taken over one hour was typically less than $0.4 \%$. If the primary reagent ion count is excluded from the background scan when investigating such statistical variation in the instrument baseline, the typical total ion count variation rises to $\sim 3 \%$.

In order to allow the instruments to measure the OVOCs at various mixing ratios, the synthetic air sample matrix was diluted twice during each day. Consequently, each experiment was composed of three individual sub-experiments termed $\mathrm{A}, \mathrm{B}$ and $\mathrm{C}$, during which the OVOCs were sampled at mixing ratios of roughly $6-10,2-3$ and $0.6-1 \mathrm{ppbV}$, respectively (for example, see Fig. 2). Because of constraints imposed by SAPHIR and the minimum sampling time required by some instruments present, the minimum length of each subexperiment was set to $3 \mathrm{~h}$. The total length of each daily experimental period was of the order of $10-12 \mathrm{~h}$.

During each experiment chamber relative humidity was monitored using a frost point hygrometer (General Eastern model Hygro M4) and ozone concentrations were measured on-line (ca. 90 s) through UV absorption (Ansyco O341M). In order to maintain a given relative humidity and ozone mixing ratio throughout the entire day and hence to account for the effects of dilution, compensation injections were made during the flushing phases between sub-experiments. Ozone and OVOC concentrations and experiment duration were all designed to be sufficiently low to ensure that ozonolysis reactions, and hence loss of susceptible OVOCs, would be insignificant.

\subsection{Calibration}

In order to facilitate absolute quantification of OVOCs detected during the intercomparison experiments, the CIR-TOF-MS was calibrated using three separate multicomponent gas mixtures containing compounds of known concentration (Air Environmental, Inc., courtesy of University of Bristol, U.K. and Paul Scherrer Institut, Ch., compound mixing ratio accuracy $\pm 10 \%$ ). Two separate phases of calibration were conducted, first of all during and then subsequently after the intercomparison, from which an instrument sensitivity was determined for each of the target OVOCs, with one exception. In the case of acetic acid methyl ester no calibration standard was available, hence a calculated sensitivity was employed.

As an example, Fig. 3 shows a methanol calibration curve acquired by the CIR-TOF-MS. The data presented therein has been normalised to $10^{6}$ primary reagent ion counts and the instrument background signal has been subtracted. Oneminute precision during calibration was of the order 5-30\% over the mixing ratio range $80-5 \mathrm{ppbV}$. These values are typical for OVOC calibration of the CIR-TOF-MS.

Following Warneke et al. (2001), the instrument sensitivity is defined as the number of ion counts acquired by the instrument per ppbV, following normalisation of the entire mass scan to $10^{6}$ primary CI reagent ion counts $\mathrm{s}^{-1}$ (units: ncps 


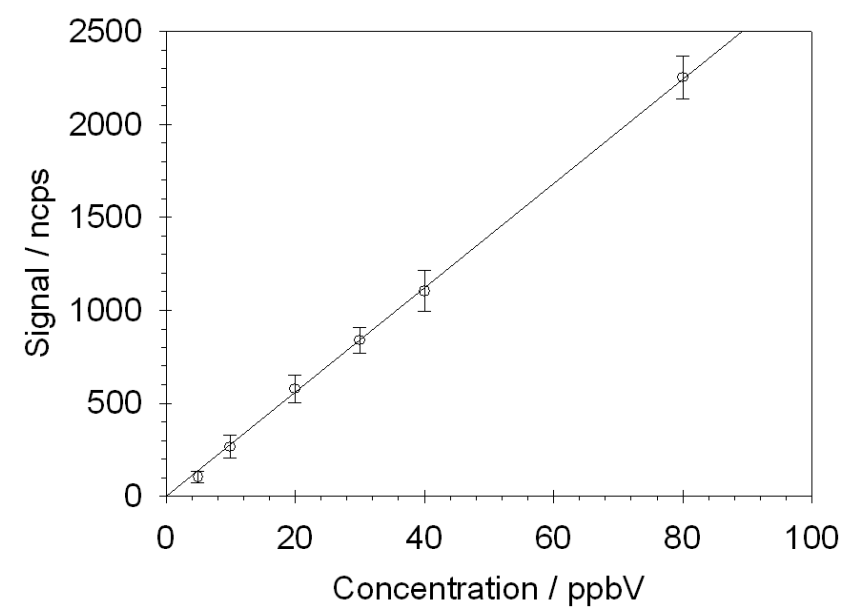

Fig. 3. Typical methanol calibration curve, derived from 10-min data acquisition per calibrant concentration at an $E / N$ of $147 \mathrm{Td}$. Correlation coefficient $\left(r^{2}\right)=0.998$.

$\mathrm{ppbV}^{-1}$ ), for each test compound under inspection (under a given, constant set of measurement conditions), viz:

Sensitivity $=\frac{\left(\text { Norm } . \mathrm{MH}^{+} \text {counts per second }\right)}{(\text { Concentration of } \mathrm{M} \text { in } \mathrm{ppbV})}$

With knowledge of the reaction kinetics inside the drift cell, e.g. reaction rate constant, time and fragmentation behaviour, it is possible to determine an instrument sensitivity for a given compound without an experimentally derived calibration curve. With no experimentally derived sensitivity value available for the quantification of acetic acid methyl ester, a theoretical sensitivity was calculated using the steady state approximation in Eq. (2). Equation (2) can be derived from reaction $(\mathrm{R} 1)$ assuming that the proton transfer reaction obeys pseudo first order conditions:

$i\left(\mathrm{MH}^{+}\right) \approx i\left(\mathrm{H}_{3} \mathrm{O}^{+}\right)_{0}[\mathrm{M}] k t$

$\mathrm{H}_{3} \mathrm{O}^{+}+\mathrm{M} \rightarrow \mathrm{MH}^{+}+\mathrm{H}_{2} \mathrm{O}$

In Eq. (2), $i\left(\mathrm{MH}^{+}\right)=$normalised, protonated analyte ion signal (ncps), $i\left(\mathrm{H}_{3} \mathrm{O}^{+}\right)_{0}=$ hydronium ion signal $\left(10^{6}\right.$ counts per second), $[\mathrm{M}]=$ analyte concentration $\left(\right.$ molecule $\mathrm{cm}^{-3}$ ), $k=$ proton transfer rate constant $\left(\mathrm{cm}^{3}\right.$ molecule $\left.{ }^{-1} \mathrm{~s}^{-1}\right)$ and $t=$ reaction time (s) (e.g. Blake et al., 2004; Hansel et al., 1995).

\section{Results and Discussion}

\subsection{Preliminary observations}

All mass scans recorded during the intercomparison exercise have been normalised to $10^{6} \mathrm{H}_{3} \mathrm{O}^{+}$ion counts and have been
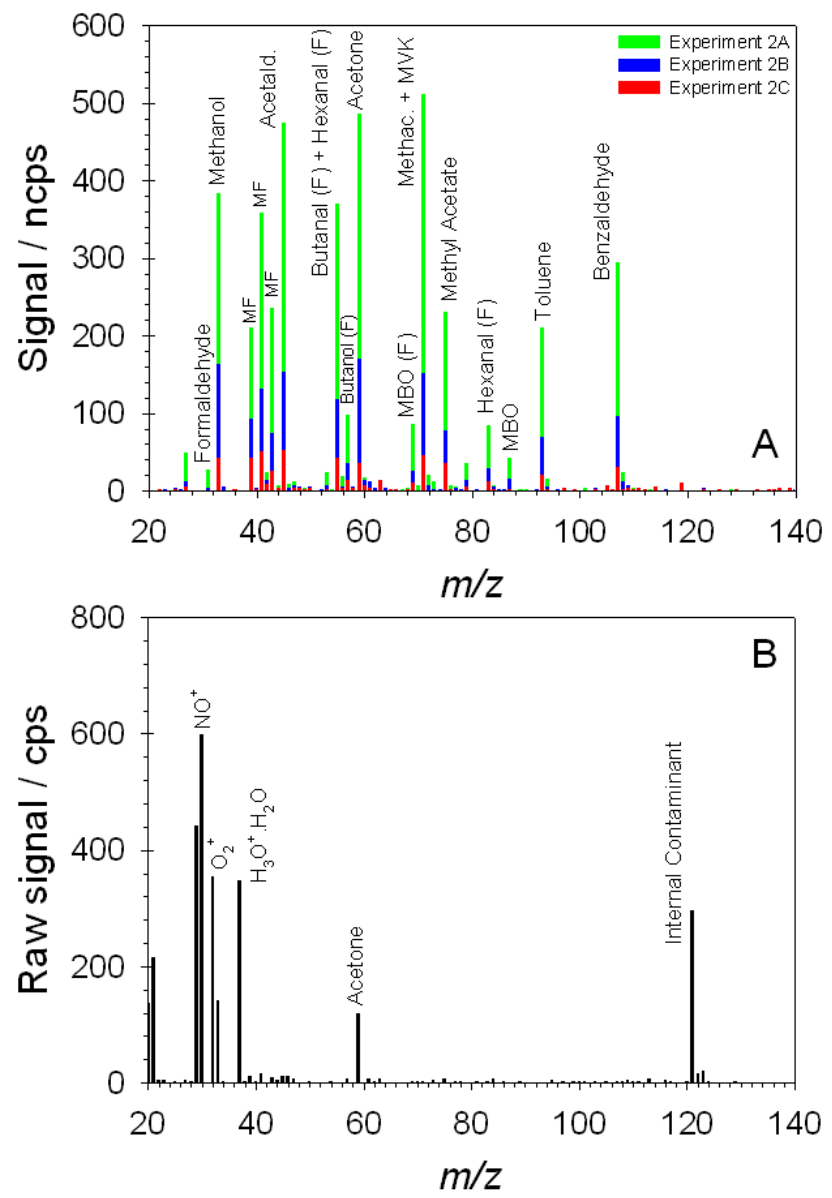

Fig. 4. (a) Mass spectra for the OVOCs recorded during experiment 2. Compound names followed by the letter F indicate fragment ions and the identifier MF signifies a mass channel occupied by a number of fragment ions originating from more than one parent compound. Green peaks give data recorded from experiment $2 \mathrm{~A}$, red from $2 \mathrm{~B}$ and blue from $2 \mathrm{C}$ (see text for details). (b) Typical background mass spectrum.

processed by subtracting an appropriate normalised background scan. The residual spectrum therefore contains only those peaks produced by reaction of $\mathrm{H}_{3} \mathrm{O}^{+}$with the target OVOCs. Figure 4a shows an example mass spectrum from experiment 2 , in which the data have been grouped by subexperiment

Initial inspection of the spectrum shows the clear presence of 14 out of the 16 intercompared compounds, 10 of which were unambiguously observed as protonated parent ion peaks. $n$-butane was not observed in the mass spectra, which was expected given the unfavorable proton affinity. As can be seen from Fig. 4a, ethanol does not appear in the mass spectrum either as the protonated parent $(m / z=47)$ or as a fragment ion. Subsequent experiments have proven the technique capable of detecting protonated ethanol but only with 

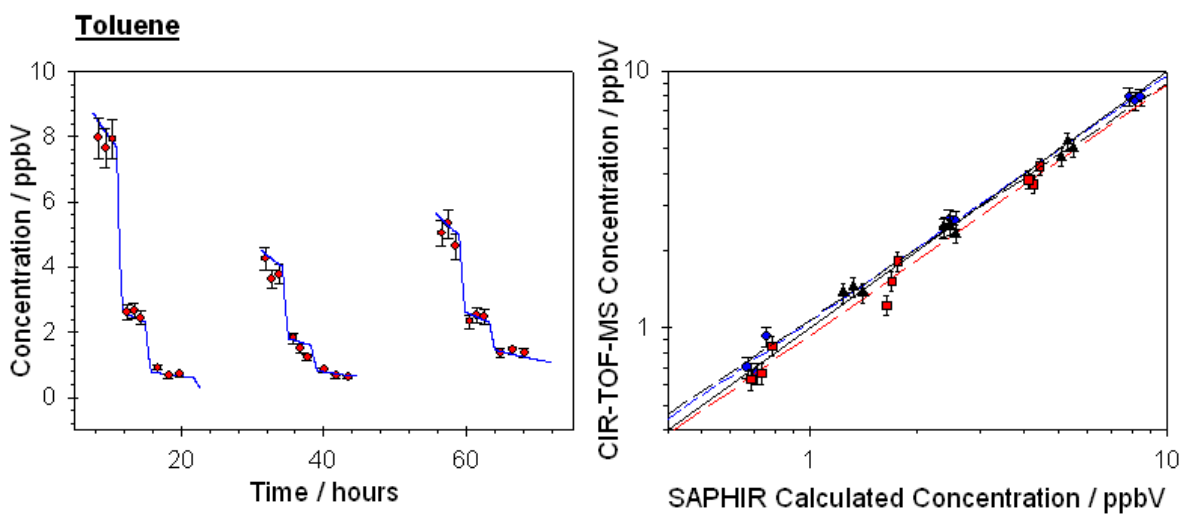

Butanal
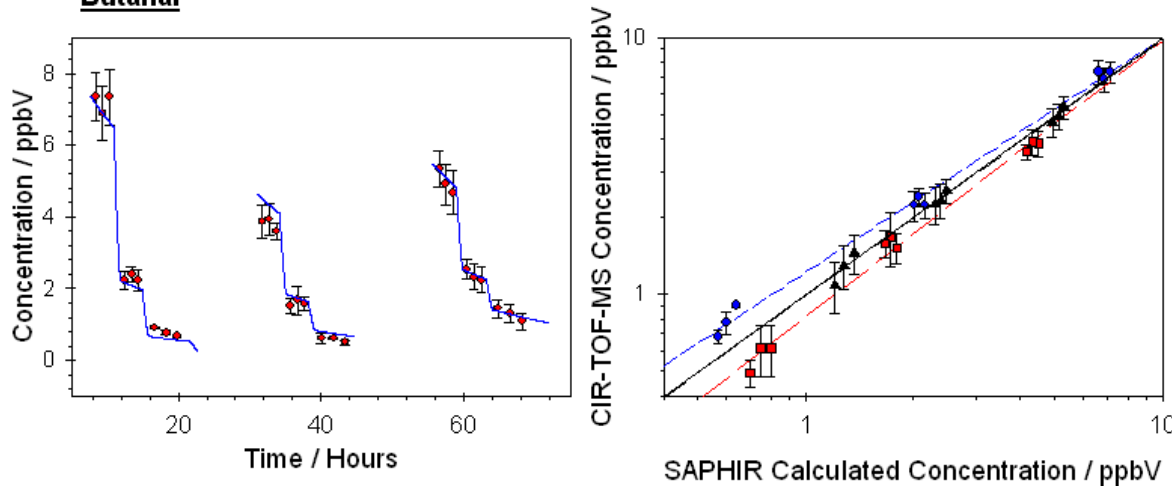

Fig. 5. Comparison of CIR-TOF-MS measured concentrations (red circles) with chamber values (blue line) throughout all experiments for toluene and butanal and their corresponding regression plots (in regression plots blue circles $=$ experiment 2 , red squares $=$ experiment 3 and black triangles $=$ experiment 4$)$. Individual correlation $\left(r^{2}\right)$ coefficients: toluene $0.993,0.996$ and 0.997 , butanal $0.995,0.995$ and 0.996 for experiments 2, 3 and 4 . The 1:1 line is plotted as the black solid line in the righthand panels.

softer drift cell conditions $(<120 \mathrm{Td})$ and at higher ethanol mixing ratios (of the order $1 \mathrm{ppmV}$ ). As reported in work by Warneke et al. (2003) it is currently believed that following the proton transfer reaction the protonated ethanol ion (observed relative abundance $\sim 50 \%$ ) will undergo some degree of fragmentation, resulting in the production of daughter ions of $m / z=29$ (observed relative abundance $\sim 50 \%$ ) and 19 (relative abundance unknown). Clearly, with a mass fragment occupying the same channel as the primary reagent ion $(m / z=19)$, monitoring ethanol using the PTR-MS technique can become somewhat problematic. With measurements made by Warneke et al. (2003) at a lower $E / N$ than that used during this study (106 Td rather than $147 \mathrm{Td}$ ) it is reasonable to assume that the majority of the ethanol ionised in the custom drift cell of the CIR-TOF-MS suffered fragmentation to mass channel 19 and hence its detection was masked by the reagent ion signal.

Figure 4a demonstrates that along with generation of $\mathrm{MH}^{+}$ ions, a substantial degree of fragmentation occurs in the drift cell, with a further eight major spectral peaks present owing to the formation of daughter ions. Compound characterization has enabled identification of each fragment peak and has revealed substantial population of mass channels 39 , 41 and 43 with daughter ions derived from most carbonyl species (Wyche et al., 2005). The significant fragmentation, and the subsequent spectral congestion, has been attributed to the heightened translational kinetic energies applied to the ions by the drift cell electric field. Under current operating conditions the average centre-of-mass kinetic energy of the ions in collisions with the neutral molecules is typically of the order 0.32-0.36 eV (Blake et al., 2006).

The specific analyte ion used for compound quantification (generally the most abundant product), its relative abundance and corresponding sensitivity is listed in Table 1 . In the case of butanal (fragment $m / z=55$ ) and propanal (fragment $m / z=41$ ), contributions to the spectral peak from daughter ions of other compounds had first to be removed.

The general observations noted here for experiment 2 apply also to experiments 3 and 4 .

Under the drift cell conditions employed throughout the intercomparison, typical ratios of hydronium to monohydrate for experiments 2, 3 and 4 were of the order 290:1, 130:1 and 140:1. 
Table 1. Physical data and CIR-TOF-MS performance statistics for target compound.

\begin{tabular}{|c|c|c|c|c|c|c|c|c|c|}
\hline Compound & $\begin{array}{l}\text { Proton affinity } \\
/ \mathrm{kJ} \mathrm{mol}^{-1}\end{array}$ & $\begin{array}{l}\text { Vapour } \\
\text { pressure } \\
/ \mathrm{mmHg}^{\mathrm{a}, \mathrm{b}}\end{array}$ & $\begin{array}{l}\text { Data ion }{ }^{\mathrm{c}} \mathrm{m} / z \\
\text { (\% abundance) }\end{array}$ & $\begin{array}{l}\text { Instrument } \\
\text { sensitivity } \\
\text { /ncps ppbV }\end{array}$ & $\begin{array}{l}\text { Accuracy }{ }^{\mathrm{d}} \\
\%(\text { Exp. 2/3/4) }\end{array}$ & $\begin{array}{l}\text { Precision }^{\mathrm{d}} \\
\%(\text { Exp. 2/3/4) }\end{array}$ & Slope & Offset & $\begin{array}{l}\text { Correlation } \\
\text { coefficient }\end{array}$ \\
\hline Acetaldehyde & 769.0 & 755 & $45(47 \%)$ & 49.8 & $13.5 / 21.9 / 3.8$ & $4.0 / 7.0 / 3.2$ & 1.01 & -0.06 & 0.995 \\
\hline Acetic acid methyl ester & 821.6 & & $-\mathrm{e}$ & 40.1 & $24.6 / 15.9 / 12.4$ & 7.3/7.0/4.4 & 0.71 & 0.41 & 0.994 \\
\hline Acetone & 812.1 & 184 & $59(100 \%)$ & 50.8 & $26.4 / 14.7 / 10.0$ & $23.4 / 15.4 / 11.0$ & 1.1 & -0.28 & 0.972 \\
\hline Benzaldehyde & 834.0 & $4^{\mathrm{f}}$ & 107 & 57.4 & $31.9 / 36.9 / 35.4$ & $5.1 / 8.1 / 6.5$ & 0.62 & 0.06 & 0.992 \\
\hline Butanal & 792.7 & 90 & $107(99 \%)$ & 57.4 & $14.6 / 14.7 / 3.9$ & $6.5 / 5.5 / 4.5$ & 1.00 & -0.05 & 0.995 \\
\hline 1-Butanol & 789.2 & 4 & $57(79 \%)$ & 48.3 & $64.2 / 72.2 / 55.8$ & $14.4 / 28.1 / 8.4$ & 0.29 & 0.15 & 0.966 \\
\hline Ethanol & 776.4 & 45 & $-\mathrm{g}$ & - & - & - & - & - & - \\
\hline Formaldehyde & 712.9 & & $-\mathrm{h}$ & - & - & - & - & - & - \\
\hline Hexanal & & 10 & $83(52 \%)$ & 9.7 & $18.7 / 28.2 / 31.4$ & $6.9 / 11.2 / 11.2$ & 0.89 & 0.64 & 0.970 \\
\hline Methanol & 754.3 & 98 & $33(100 \%)$ & 28.0 & $25.7 / 25.5 / 37.6$ & $20.2 / 25.5 / 20.4$ & 0.77 & 0.58 & 0.915 \\
\hline 1-Propanol & 786.5 & 15 & $41(51 \%)$ & 45.7 & $25.2 / 21.3 / 16.2$ & $12.0 / 11.4 / 5.2$ & 0.60 & 0.60 & 0.998 \\
\hline Methacrolein + MVK & 834.7 & $121 / 71$ & $71(>87 \%)^{\mathrm{i}}$ & 40.9 & $17.9 / 15.8 / 4.5$ & $2.8 / 3.2 / 3.2$ & 0.83 & 0.03 & 0.998 \\
\hline 2 methyl-3-buten-2-ol & & $51^{\mathrm{j}}$ & $87(16 \%)$ & 6.6 & $27.0 / 25.5 / 24.4$ & $31.2 / 27.4 / 17.2$ & 0.87 & -0.02 & 0.957 \\
\hline Toluene & 784.1 & 22 & $93(100 \%)$ & 26.0 & $6.8 / 10.0 / 6.2$ & $7.0 / 10.1 / 6.3$ & 0.95 & 0.06 & 0.995 \\
\hline
\end{tabular}

a Vapor pressures measured at $20^{\circ} \mathrm{C}$ unless otherwise noted,

b http://www.sigmaaldrich.com,

${ }^{\mathrm{c}}$ Ion employed for compound quantification, value given as a percentage contribution to the total ion count of that compound,

${ }^{\mathrm{d}}$ See text for details,

e Calculated sensitivity employed (see text for details),

$\mathrm{f}^{\mathrm{V}}$ Vapor pressure measured at $45^{\circ} \mathrm{C}$,

g Compound not detected,

${ }^{\mathrm{h}}$ Compound measurements not reported upon within this paper,

${ }^{\mathrm{i}}$ Methacrolein relative abundance $87 \%$ and methyl vinyl ketone relative abundance $95 \%$,

$\mathrm{j}$ Vapor pressure measured at $25^{\circ} \mathrm{C}$.

3.2 Comparison with chamber values: measurement accuracy, precision and linearity

In order to ascertain information regarding the ability of the CIR-TOF-MS to quantitatively measure the detected OVOCs both reliably and reproducibly, a comparison has been made between measured concentrations and estimated chamber values, which have been determined from knowledge of the amount of liquid OVOC initially injected into SAPHIR and the air dilution rates over time. It should be noted however that such estimated chamber concentrations are not definitive and may vary from the actual ambient concentration of any given OVOC in the chamber at any point by up to $20 \%$. Effectively, the estimated chamber OVOC concentrations represent an upper limit of the true values (Wegener and Holzke, personal communication, 2004).

For the purpose of comparison between measured and estimated chamber concentrations, the CIR-TOF-MS data have been integrated over periods of approximately $50 \mathrm{~min}$ for each sub-experiment, producing three repeat measurements at each concentration. The only exceptions to this are the data for all part $\mathrm{C}$ sub-experiments, where the integration time was approximately $90 \mathrm{~min}$. Figure 5 shows such a comparison for toluene and butanal, in which measured concentrations are displayed as red points with error bars and estimated values are shown with a blue line. Close inspection of Fig. 5 reveals that there is a small slope in the OVOC concentration profile throughout each measuring period owing to dilution as the chamber is kept at a constant pressure. Corresponding correlation plots for experiments 2, 3 and 4 for both toluene and butanal are also given in Fig. 5 .

Table 1 shows the accuracies, precisions, slopes, offsets and correlation coefficients that have been obtained for each of the detected compounds (excluding formaldehyde, a special case discussed later). In this instance we define the compound specific instrument accuracy as the modulus of the percentage excursion of the CIR-TOF-MS measured concentration from the estimated chamber value, simply calculated from the ratio of the former to the latter. The precision values quoted here have been calculated from the ratio of the standard error of the mean in a given data set of repeats to that of the specific mean value. Again the resultant figure is expressed as a percentage. All values have been averaged over the nine measurements taken during the three subexperiments of a single day. The correlation coefficients $\left(r^{2}\right)$ given in Table 1 were obtained by averaging over the individual $r^{2}$ coefficients of experiments 2, 3 and 4 and with no forcing of the data through the origin. All values of slope and intercept have been produced from the entire data set for each compound. 


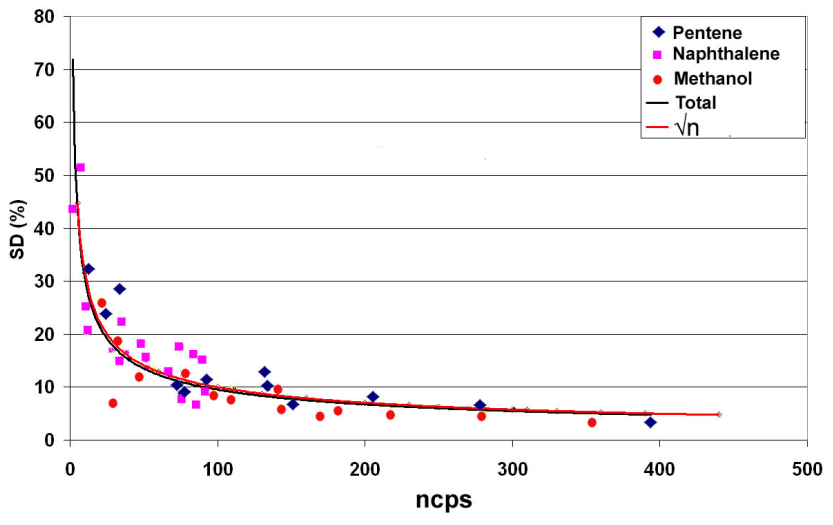

Fig. 6. Percentage standard deviation against count (ncps) for range of hydrocarbons.

Ion signals for the target OVOCs, integrated over the specific time periods as detailed above, possessed good signalto-noise ratio $(S / N)$, generally far in excess of 3:1 (the usual criterion employed in order to determine whether a signal is discernable). All $S / N$ values were calculated according to Eq. (3):

$S / N=\frac{S_{a v}}{\sqrt{ }\left(\bar{S}_{n}^{2}\right)}$

In Eq. (3), $S_{a v}=$ the average ion signal in a given mass channel taken over the entire measuring period and $S_{n}=$ the ion signal (in the stated mass channel) obtained during the $n$th measurement, hence $\sqrt{ }\left(\bar{S}_{n}^{2}\right)=$ the root-mean-square noise (Wayne, 1995).

The compound specific $S / N$ ratios presented by the OVOC signals shown in Fig. 4 for sub-experiments A, B and C lay within the ranges $17-270,19-178$ and 3-50, respectively. These values were typical across all experiments. It is worth noting, as shown in Fig. 6, that the data have an inherent $\sqrt{ } n$ dependence with respect to the standard deviation of the ion count with decreasing signal count.

Generally, most species were measured by the CIR-TOFMS with an average accuracy of around $25 \%$ or better, with the compounds acetaldehyde, butanal and toluene consistently measured with the greatest accuracy throughout the exercise. Particularly high measurement accuracies were achieved for these three compounds during all part A subexperiments, where values were on average $5.5 \%$ for mixing ratios of the order $10 \mathrm{ppbV}$.

Of the 14 compounds detected, hexanal, 1-butanol and benzaldehyde proved the most difficult to monitor with respect to accuracy. The data in Fig. 7 suggests that the poor accuracies achieved for hexanal could be attributed to an inadequate estimation of the instrument base line. Figure 7 shows an increase in the ratio of measured to estimated chamber

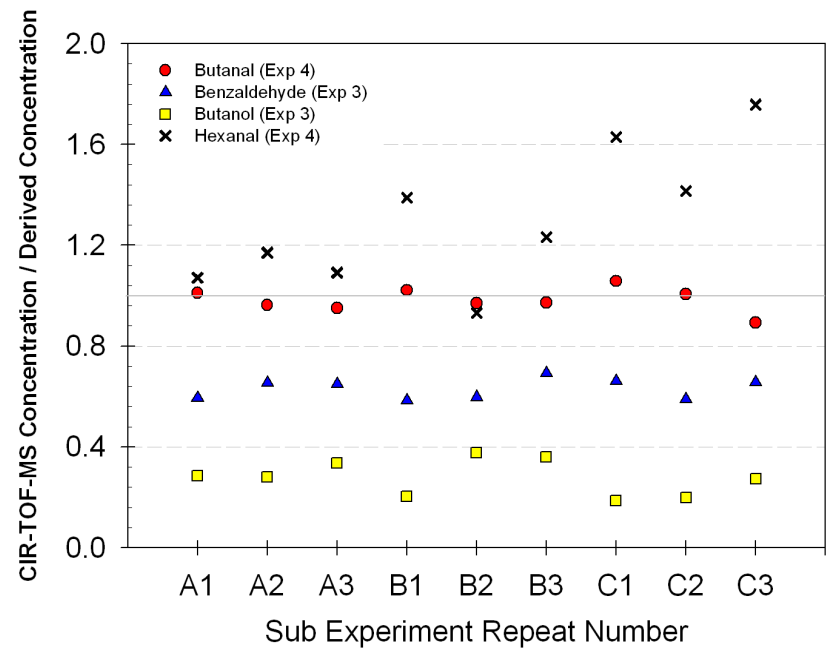

Fig. 7. Concentration versus sub-experiment number scatter plot for butanal, benzaldehyde, butanol and hexanal. Experiment subnumber refers to the individual sub-experiment (For example, A1, A 2 and A3 represent the 3 repeat measurements taken for each subexperiment A) conducted during either experiment 3 or 4 (see legend).

concentrations as the chamber air was diluted, which tends to imply that data extracted from the hexanal peak at $m / z=83$ contained a residual, unknown quantity of contamination not fully removed during background subtraction. Inspection of Table 1 reveals that hexanal has the largest (positive) intercept value of all of the compounds (+0.638) further supporting this premise.

In the case of 1-butanol and benzaldehyde, the CIR-TOFMS consistently underestimated the derived chamber concentrations. Figure 7 demonstrates this and verifies a roughly constant percentage difference between calculated and those measured. Such findings are consistent with the presence of an unknown sink for these compounds on route to detection.

Table 1 shows that benzaldehyde and 1-butanol have the lowest vapor pressures of the target compounds $(4 \mathrm{mmHg}$ at 45 and $20^{\circ} \mathrm{C}$ respectively), making these the most likely candidates to undergo condensation out of the vapour phase. The possibility of sink/loss via this route is reinforced by consideration of the average ambient temperatures throughout the campaign, which were consistently low, in the range -1 to $+4^{\circ} \mathrm{C}$. With such compound loss not accounted for in the estimated chamber concentrations, deposition in this manner could lead to the poor measurement accuracy obtained in this instance.

As can been seen in Fig. 4a the CIR-TOF-MS, operating in PTR mode, was able to detect only a minor formaldehyde signal. Hansel et al. (1997) have demonstrated that formaldehyde is difficult to measure using the PTR-MS technique. This difficulty results from the kinetics of the proton transfer reaction, the exothermicity of which is relatively low, as 
is the endothermicity of the backwards reaction between the $\mathrm{HCHO} . \mathrm{H}^{+}$ion and the neutral water molecule. As noted by Hansel and co-workers, the energy supplied to the reactant ions by the drift cell electric field is sufficiently large to allow loss of the protonated formaldehyde ion via the back reaction, reducing any formaldehyde signal. With the CIR-TOFMS not yet fully characterised for detection of formaldehyde, no values are reported within this work for its accuracy and precision of measurement.

Measurement reproducibility throughout each experiment was generally high, with compound specific instrument precision of the order $10 \%$ or better for most species. However, the results for acetone and methanol are an exception to this statement, where the greater scatter can be attributed to minor internal instrument contamination of these species during the intercomparison campaign. Such problems could easily be removed by a better estimate of the instrument baseline at the time of measurement.

The CIR-TOF-MS response was found to be strongly linear over the concentration range investigated, with correlation coefficients $\left(r^{2}\right)$ ranging between 0.975 and 0.998 for the chosen set of compounds under dry sample conditions. Overall for most of the test compounds the slope in the data was close to 1 , with 1-butanol being the major outlier (slope $=0.287$ ). In general, the offset of each data set was around $0.5 \mathrm{ppbV}$ or less

\subsection{Effect of humidity and ozone}

In proton transfer reaction mass spectrometry a compound is generally insensitive to the presence of water vapour if it is able to react at a collision-limited rate with hydrated hydronium ions $\mathrm{H}_{3} \mathrm{O}^{+} .\left(\mathrm{H}_{2} \mathrm{O}\right)_{n}$ (where $n \geq 1$ ), via ligand switching, dissociative or otherwise. In order to react the compound under inspection must possess a proton affinity greater than that of the reagent cluster ion and have a sufficiently large dipole moment. These are properties which some of the test compounds do not possess (Španěl and Smith, 1995, 2000).

In general, when employing proton transfer reaction ionisation the presence of $\mathrm{H}_{3} \mathrm{O}^{+} .\left(\mathrm{H}_{2} \mathrm{O}\right)_{n}$ ions in the reaction drift cell can lead to a more complex and convoluted mass spectrum with the production of not only the $\mathrm{MH}^{+}$ion following direct proton transfer, but also $\mathrm{MH}^{+} .\left(\mathrm{H}_{2} \mathrm{O}\right)_{n}$ ions and fragments thereof. In order to remove such unwanted signals from the mass spectrum, the water cluster ion abundance with respect to that of the primary reagent ion can be minimised by applying a relatively large electric field along the drift cell. Additionally, to facilitate further the removal of $\mathrm{MH}^{+} .\left(\mathrm{H}_{2} \mathrm{O}\right)_{n}$ ions and to assist focusing of the ion beam, the electrical potential gradient at the base of the CIR drift cell is ramped to around $1440 \mathrm{~V} \mathrm{~cm}^{-1}$ over a $1.7 \mathrm{~mm}$ collision cell before entry into the mass spectrometer.

With the present instrument configuration and under the drift cell conditions described here (i.e. $\sim 147 \mathrm{Td}$ with exit potential ramp) the measured monohydrate yield was typi- cally $\sim 0.4 \%$ of the hydronium ion yield during experiment 2 , in which the OVOCs were sampled from a dry synthetic air matrix. The measured yield of monohydrate with respect to that of the hydronium ion increased to only $\sim 0.8 \%$ when sample humidity was raised to approximately $100 \%$ during experiment 3. Correspondingly, little variation was observed in the hydronium abundance between dry and moist conditions, with the mean count rate at $100 \%$ relative humidity within one standard deviation of that seen during dry sampling.

Despite these observations the removal of water cluster ions by the potential ramp at the base of the drift cell will mask the true distribution of reagent ions present in the main drift cell above the collision region. If the ramping field applied to the collision region is reduced to 1230 and $1030 \mathrm{~V} \mathrm{~cm}^{-1}$ the yield of monohydrate with respect to that of the hydronium ion increases to $\sim 6.5$ and $23.1 \%$ respectively.

Inspection of Table 1 shows that for the majority of the test compounds, measurement accuracy and precision was unaffected by the introduction of humidity into the sample matrix, with the only significant exception being hexanal. The origin of this decrease in accuracy lies in interference effects, with hexanal fragmenting following proton transfer ionisation to yield a significant fragment ion at $m / z=55$, which is isobaric with the hydronium-water cluster ion $\mathrm{H}_{3} \mathrm{O}^{+} .\left(\mathrm{H}_{2} \mathrm{O}\right)_{2}$.

Additionally, inspection of Table 1 indicates that there was no significant effect on measured accuracy and precision for the majority of the test compounds following addition of ozone to the sample matrix. The only two exceptions to this are methanol and hexanal, whose poor accuracy and precision values for experiment 4 can be explained through background interference in their respective mass channels. With a total inlet residence time of only 11 seconds for the sample gas on route to the drift cell and with relatively low ozone concentrations in the sample matrix (of the order 40$50 \mathrm{ppbV}$ ), any possible ozone/surface effects during measurement using the CIR-TOF-MS technique are expected to be minimal.

\subsection{Real-time monitoring and time-of-flight mass spec- trometry}

One major advantage of the CIR-TOF-MS technique is its ability to monitor a multitude of trace compounds in realtime, which we define as time scales of one minute or less. This is exemplified, in respect of real-time, in Fig. 2, which displays the data recorded for acetaldehyde during experiment 2 alongside the estimated chamber concentrations.

As expected the typical signal-to-noise ratio for all oneminute data was substantially lower than the equivalent value achieved following fifty-minute integration, across all values of mixing ratio. For example, over the entire experiment sub-section, the one-minute acetaldehyde data recorded during experiment 2 possessed average $S / N$ ratios of $8: 1,5: 1$ 


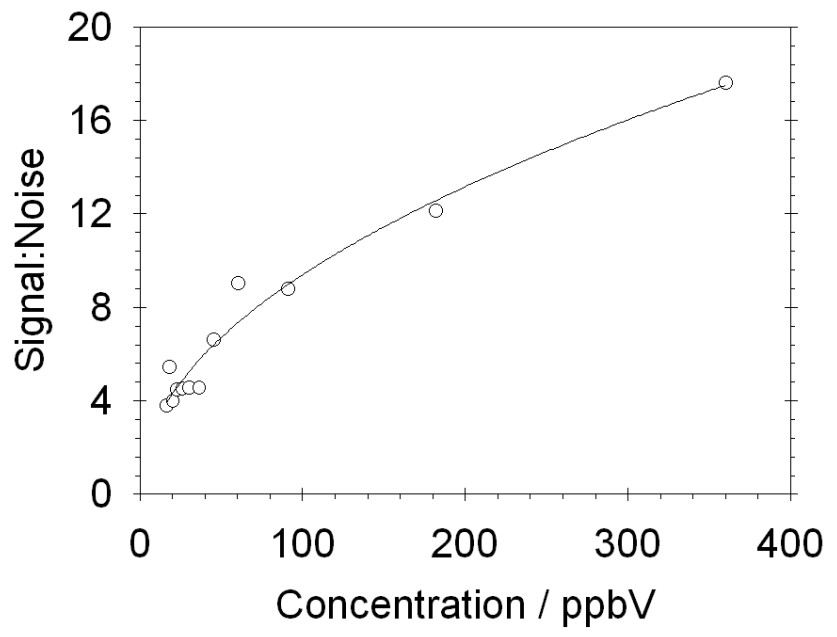

Fig. 8. Signal: noise ratio versus concentration for the OVOC 2-hexanone. Data fit with a power law, equation: $S / N=1.0017 \times$ Concentration $^{0.486}$.

and $4: 1$ at concentrations of around 10,3 and $1 \mathrm{ppbV}$ respectively. With the exception of hexanal and MBO, for which sensitivities were considerably low, the average $S / N$ ratios in the one-minute data for most compounds were in the range 2-3:1 or greater for both sub-experiments A and B.

The detection limit of the CIR-TOF-MS for a given compound, can be determined through knowledge of the signalto-noise ratios achieved during measurement of that target compound at a number of concentrations over a wide mixing ratio range. In Fig. 8 a plot is made of $S / N$ ratio versus concentration for 2-hexanone. The data presented demonstrates that in the CIR-TOF-MS there exists a power law relationship between $S / N$ ratio and measured concentration. The limit of detection can subsequently be found by extrapolating the curve backwards to a point where the $S / N$ ratio is such that the signal becomes indiscernible. In the given example, 2-hexanone has a $60 \mathrm{~s}$ detection limit of $4.1 \mathrm{ppbV} \mathrm{min}^{-1}$ at $S / N=2: 1$. Table 2 contains example 1-minute detection limits for some atmospheric OVOCs used in this study,

During sub-experiment 2A, where mixing ratios were of the order of $10 \mathrm{ppbV}$, average one-minute accuracy for acetaldehyde over the entire three-hour period was exceptionally good at $12.5 \%$, comparing remarkably well with the fifty-minute data. One-minute precision was also comparable, at $15.4 \%$. However, as the chamber air was diluted and mixing ratios decreased, accuracy and precision both fell. In the case of acetaldehyde, accuracy and precision values were $32.4 \%$ and $66.7 \%$ respectively for sub-experiment $2 \mathrm{~B}$ and $37.7 \%$ and $76.3 \%$ for sub-experiments $2 \mathrm{C}$.

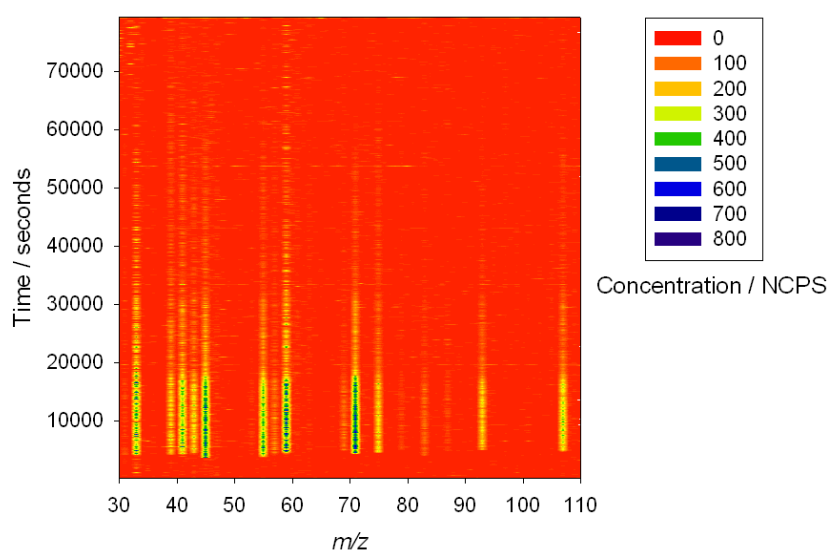

Fig. 9. Illustration of the ion count in all mass channels with time (data taken from experiment 2).

Table 2. One minute detection limit for typical atmospheric OVOCs assuming a power law relationship (see Fig. 8) between OVOC concentration and signal-to-noise ratio.

\begin{tabular}{lll}
\hline Compounds & Mass (amu) & $\begin{array}{l}\text { Detection Limit } \\
\left(\text { counts } \mathrm{pbV}^{-1}\right)\end{array}$ \\
\hline methanol & 32 & 14.98 \\
acetaldehyde & 44 & 6.33 \\
methacrolein & 70 & 25.55 \\
2-hexanone & 100 & 4.23 \\
\hline
\end{tabular}

Combining the benefits of fast and reliable data acquisition with time-of-flight mass spectrometry allows the construction of a highly detailed picture of the sample matrix, in which all mass channels are observed simultaneously, unlike conventional quadrupole instruments where only a single mass channel is monitored at any instant in time. As a result this technique allows even the most complex and transient events to be monitored in high detail. This is exemplified in Fig. 9, which shows the normalised ion count acquired in each mass channel of the CIR-TOF-MS throughout experiment 2 of the intercomparison. Close inspection of Fig. 9 reveals features typical to each of the intercomparison experiments (e.g. see Fig. 2), including three distinct measurement periods and the two dilution events.

\subsection{Sensitivity intercomparison}

In order to present a measure of relative instrument performance a brief comparison is made between sensitivities acquired by the CIR-TOF-MS for a number of common atmospheric VOCs with published experimental sensitivities obtained by several other PTR-MS instruments. Included in this comparison are findings by Ennis et al. (2005), Hanson 
Table 3. Sensitivity comparison between four different PTR-MS instruments (all sensitivities are given in ncps/ppbV).

\begin{tabular}{lllll}
\hline & This work & $\begin{array}{l}\text { Ennis et al. } \\
2005\end{array}$ & $\begin{array}{l}\text { Hanson et al. } \\
2003\end{array}$ & $\begin{array}{l}\text { de Gouw et al. } \\
2003\end{array}$ \\
\hline$E / N / T d$ & 147 & $\sim 120$ & $\sim 114$ & - \\
\hline methanol & 28 & - & $60-30$ & 24 \\
acetaldehyde & 50 & - & $115-90$ & 27 \\
acetone & 51 & 28 & 240 & 64 \\
toluene & 26 & 4 & - & 45 \\
\hline
\end{tabular}

et al. (2003) and de Gouw et al. (2003) for the detection of methanol, acetaldehyde, acetone and toluene (see Table 3). The relative normalised sensitivity values given in Table 3 were obtained by the various authors under a range of drift cell conditions $(E / N$ from $\sim 110-147 \mathrm{Td}$ ), with each instrument individually optimised for the detection of such trace species.

The CIR-TOF-MS sensitivities for acetone and toluene obtained in this work are significantly larger than those obtained by Ennis and co-workers, who operate a similar time-offlight instrument (Kore Technology Ltd), which is coupled to a hollow cathode ion source. Our instrument sensitivities compare favourably with results from de Gouw et al. (2003), obtained during the New England Air Quality Study in 2002, using a conventional discharge ion source/quadrupole device (Ionicon Analytik). The CIR-TOF-MS sensitivity is slightly greater in the cases of methanol and acetaldehyde than was achieved by de Gouw, but slightly lower in the case of acetone and toluene.

Sensitivities obtained by the CIR-TOF-MS also compare reasonably with results from the PTR-MS of Hanson et al. (2003), which comprises a similar radioactive ion source alternatively coupled to a quadrupole mass spectrometer. Results taken from Hanson et al. (2003) (Table 3) are given as a range in order to cover the different sensitivities achieved under various sample humidities, with the larger sensitivities achieved under less humid conditions. Our (dry) compound sensitivities were around 3-4 times lower than Hanson's with the major differences being attributed to the higher working pressure of that drift tube.

\section{Conclusions}

The data presented demonstrate that chemical ionisation reaction time-of-flight mass spectrometery is capable of providing highly accurate and reproducible measurements of a wide range of atmospherically important OVOCs. The instrument performance with respect to the measurement of a range of OVOCs has been quantified. It has been demonstrated that a time-of-flight device is capable of providing on-line measurements of atmospheric trace species, with rel- ative sensitivities entirely comparable to similar commercial quadrupole based instruments. The potential benefits of using a TOF based device for atmospheric monitoring are considerable, with the sample matrix being probed in more depth and detail than has been possible previously.

Acknowledgements. The EU project ACCENT and the NERC and EPSRC funding councils are gratefully acknowledged for providing funds to carry out this work. The authors would also like to thank C. Schieferstein, K. Wilkinson and J. Weale, for technical support in preparation for the intercomparison campaign.

Edited by: J. Abbatt

\section{References}

Apel, E. C., Calvert, J. G., Gilpin, T. M., Fehsenfeld, F., and Lonneman, W. A.: Nonmethane Hydrocarbon Intercomparison Experiment (NOMHICE): Task 4, ambient air, J. Geophys. Res.Atmos., 108(D12), 4359, doi:10.1029/2002JD002936, 2003.

Blake, R. S., Whyte, C., Hughes, C. O., Ellis, A. M., and Monks, P. S.: Demonstration of proton-transfer reaction time-of-flight mass spectrometry for real-time analysis of trace volatile organic compounds, Anal. Chem., 76(13), 3841-3845, 2004.

Blake, R. S., Wyche, K. P., Ellis, A. M., and Monks, P. S.: Chemical ionization reaction time-of-flight mass spectrometry: Multireagent analysis for determination of trace gas composition, Int. J. Mass Spectrom., 254(1-2), 85-93, 2006.

de Gouw, J. A., Goldan, P. D., Warneke, C., Kuster, W. C., Roberts, J. M., Marchewka, M., Bertman, S. B., Pszenny, A. A. P., and Keene, W. C.: Validation of proton transfer reaction-mass spectrometry (PTR-MS) measurements of gas-phase organic compounds in the atmosphere during the New England Air Quality Study (NEAQS) in 2002, J. Geophys. Res.-Atmos., 108(D21), 4359, doi:10.1029/2003JD003863, 2003.

Ennis, C. J., Reynolds, J. C., Keely, B. J., and Carpenter, L. J.: A hollow cathode proton transfer reaction time of flight mass spectrometer, Int. J. Mass Spectrom., 247(1-3), 72-80, 2005.

Hansel, A., Jordan, A., Holzinger, R., Prazeller, P., Vogel, W., and Lindinger, W.: Proton-Transfer Reaction Mass-Spectrometry Online Trace Gas-Analysis At The Ppb Level, Int. J. Mass Spectrom., 150, 609-619, 1995.

Hansel, A., Singer, W., Wisthaler, A., Schwarzmann, M., and Lindinger, W.: Energy dependencies of the proton transfer re- 
actions $\mathrm{H}_{3} \mathrm{O}^{+}+\mathrm{CH}_{2} \mathrm{O} \Leftrightarrow \mathrm{CH}_{2} \mathrm{OH}^{+}+\mathrm{H}_{2} \mathrm{O}$, Int. J. Mass Spectrom., 167, 697-703, 1997.

Hanson, D. R., Greenberg, J., Henry, B. E., and Kosciuch, E.: Proton transfer reaction mass spectrometry at high drift tube pressure, Int. J. Mass Spectrom., 223(1-3), 507-518, 2003.

Inomata, S., Tanimoto, H., Aoki, N., Hirokawa, J., and Sadanaga, Y.: A novel discharge source of hydronium ions for proton transfer reaction ionization: design, characterization, and performance, Rapid Communications in Mass Spectrometry, 20, 10251029, 2006.

Kalberer, M., Paulsen, D., Sax, M., Steinbacher, M., Dommen, J., Prèvôt, A. S. H., Fisseha, R., Weingartner, E., Frankevich, V., Zenobi, R., and Baltensperger, U.: Identification of polymers as major components of atmospheric organic aerosols, Science, 303(5664), 1659-1662, 2004.

Karl, M., Brauers, T., Dorn, H. P., Holland, F., Komenda, M., Poppe, D., Rohrer, F., Rupp, L., Schaub, A., and Wahner, A.: Kinetic Study of the $\mathrm{OH}$-isoprene and $\mathrm{O}_{3}$-isoprene reaction in the atmosphere simulation chamber, SAPHIR, Geophys. Res. Lett., 31(5), L05117, doi:10.1029/2003GL019189, 2004.

Lewis, A. C., Hopkins, J. R., Carpenter, L. J., Stanton, J., Read, K. A., and Pilling, M. J.: Sources and sinks of acetone, methanol, and acetaldehyde in North Atlantic marine air, Atmos. Chem. Phys., 5, 1963-1974, 2005, http://www.atmos-chem-phys.net/5/1963/2005/.

Lindinger, W., Hirber, J., and Paretzke, H.: An Ion/MoleculeReaction Mass-Spectrometer Used For Online Trace GasAnalysis, Int. J. Mass Spectrom. Ion Processes, 129, 79-88, 1993.

Monks, P. S.: Gas-phase radical chemistry in the troposphere, Chem. Soc. Rev., 34(5), 376-395, 2005.

Northway, M. J., de Gouw, J. A., Fahey, D. W., Gao, R. S., Warneke, C., Roberts, J. M., and Flocke, F.: Evaluation of the role of heterogeneous oxidation of alkenes in the detection of atmospheric acetaldehyde, Atmos. Environ., 38(35), 6017-6028, 2004.

Plass-Dülmer, C., Schmidbauer, N., Slemr, J., Slemr, F., and D'Souza, H.: European hydrocarbon intercomparison experiment AMOHA part 4: Canister sampling of ambient air, J. Geophys. Res.-Atmos., 111(D4), D04306, doi:10.1029/2005JD006351, 2006.

Singh, H. B., Kanakidou, M., Crutzen, P. J., and Jacob, D. J.: HighConcentrations And Photochemical Fate of Oxygenated Hydrocarbons In The Global Troposphere, Nature, 378(6552), 50-54, 1995.
Sinreich, R., Frieß, U., Wagner, T., and Platt, U.: Multi axis differential optical absorption spectroscopy (MAX-DOAS) of gas and aerosol distributions, Faraday Discuss., 130, 153-164, 2005.

Španěl, P. and Smith, D.: Reactions of Hydrated Hydronium Ions And Hydrated Hydroxide Ions, With Some Hydrocarbons And Oxygen-Bearing Organic-Molecules, J. Phys. Chem., 99(42), 15 551-15 556, 1995.

Španěl, P. and Smith, D.: Influence of water vapour on selected ion flow tube mass spectrometric analyses of trace gases in humid air and breath, Rapid Communications in Mass Spectrometry, 14(20), 1898-1906, 2000.

Warneke, C., Holzinger, R., Hansel, A., Jordan, A., Lindinger, W., Pöschl, U., Williams, J., Hoor, P., Fischer, H., Crutzen, P. J., Scheeren, H. A., and Lelieveld, J.: Isoprene and its oxidation products methyl vinyl ketone, methacrolein, and isoprene related peroxides measured online over the tropical rain forest of Surinam in March 1998, J. Atmos. Chem., 38(2), 167-185, 2001.

Warneke, C., van der Veen, C., Luxembourg, S., de Gouw, J. A., and Kok, A.: Measurements of benzene and toluene in ambient air using proton-transfer-reaction mass spectrometry: calibration, humidity dependence, and field intercomparison, Int. J. Mass Spectrom., 207(3), 167-182, 2001.

Warneke, C., de Gouw, J. A., Kuster, W. C., Goldan, P. D., and Fall, R.: Validation of Atmospheric VOC Measurement by Proton-Transfer-Reaction Mass Spectrometry using a GasChromatographic Preparation Method, Environ. Sci. Technol., 37, 2494-2501, 2003.

Warneke, C., Kato, S., De Gouw, J. A., Goldan, P. D., Kuster, W. C., Shao, M., Lovejoy, E. R., Fall, R., and Fehsenfeld, F. C.: Online volatile organic compound measurements using a newly developed proton-transfer ion-trap mass spectrometry instrument during New England Air Quality Study - Intercontinental Transport and Chemical Transformation 2004: Performance, intercomparison, and compound identification, Environ. Sci. Technol., 39(14), 5390-5397, 2005.

Wayne, R. P.: Chemical Instrumentation, Oxford, Oxford University Press, 1995.

Wyche, K. P., Blake, R. S., Willis, K. A., Monks, P. S., and Ellis, A. M.: Differentiation of isobaric compounds using chemical ionization reaction mass spectrometry, Rapid Communications in Mass Spectrometry, 19(22), 3356-3362, 2005. 